\section{El radicalismo}

Por Carlos Perez, ed. Buenos Aires, 1968. 319 p. (Coleción Los Porques?)

\section{El Radicalismo}

Luis Alberto Romero

José Luis Fernández Lilia A. Berton Juan C. Grosso Marta Calvino Susana Bianch Alberto J. Pla

Colección Los porques Carlos Perez Editor

Esta coletânea enfoca um problema fundamental da história da Argentina, o movimento radicalista, associado à figura de Hipólito Yrigoyen. Ela esclarece a atuação deste líder político desde as origens da União Cívica Radical e a conseqüente evolução deste partido.

Os artigos aqui apresentados adotam uma perspectiva de análise histórica e complementamse cronologicamente. Além disso conseguem dar ao leitor uma visão global do fenômeno do radicalismo. Neste sentido, destacam-se especialmente as contribuições de Luis Alberto Romero, El surgimiento y la llegada al poder; de Lilia Ana Bertoni, Las transformaciones del partido y sus luchas políticas (1916-1930); e de Susana Bianchi, Las contradicciones del radicalismo. Enfrentamientos com el peronismo.
Enquanto movimento político, - radicalismo veio quebrar uma ordem relativamente estável que sustentava a oligarquia no poder. Nascia num período em que um processo de modernização intentado principalmente na década de 1880 já havia alterado as condições econômicas e sociais do país. Luis Alberto Romero 'esclarece as raízes do movimento e explica como o radicalismo abandonou seu longo período de abstenção e assumiu o poder.

$\mathrm{Na}$ verdade, a década de 1880 marcou um período de expansão econômica na Argentina. As demandas do mercado externo incentivaram a intensificação da produção agropecuária, de cereais, lã e linho, além da carne. Esta expansão das atividades econômicas exigia reformas principalmente na infra-estrutura de transportes que facilitassem o escoamento destes produtos exportáveis. É por isso que a oligarquia, então dona exclusiva do poder e representante direta destes interesses, viu-se na contingência de adotar uma política econômica avançada e implantar as ditas reformas. Estas, porém, não prejudicaram o ponto estratégico do poder oligárquico: o latifúndio. Atingiram principalmente - litoral onde se concentrou a imigração e onde o processo de urbanização foi mais intenso, com o crescimento de cidades importantes como Buenos Aires, Córdoba, Santa Fé, Entre Rios, etc. Em contrapartida, este processo de modernização acarretou o aparecimento de um novo setor em condições de pressionar em termos sociais e políticos: as classes médias urbanas.

Uma crise cíclica, em 1890, veio facilitar a mobilização destes novos setores. A população viu-se prejudicada por uma crise que atingia a economia como um todo. A retração do comércio externo e das atividades agropecuárias e o aceleramento do processo inflacionário e recuo dos créditos e das inversões britânicas condicionavam a instabilidade política subseqüente. Nesta conjuntura, nascia a União Cívica, movimento de oposição que agregava os mais diversos setores descontentes e marginalizados da vida política, desde parcelas da juventude universitária, até grupos da burguesia comercial e principalmente os setores médios emergentes. Reivindicava o sufrágio universal e clamava por moralidade administrativa. Como movimento de oposição, a União Cívica lutava por incorporar-se ao sistema mas sem alterar seus fundamentos. Mas sua composição tão heterogênea teve efeitos funestos para a unidade do movimento. Surgiram logo tendências divergentes quanto à atuação política. Uma tendência conservadora agrupava setores da burguesia comercial que tinham em Mitre seu representante oficial. Por outro lado, a ala intransigente, guiada pela figura popular de Além, correspondia às aspirações da classe média emergente. Estas duas tendências foram responsáveis pela divisão da União Cívica em Nacional e Radical. A pressão destes novos grupos políticos colocava em perigo a estabilidade do governo. Esta situação agravou-se em 1893, com - levante armado em Buenos Aires e o governo foi obrigado a ceder, estabelecendo acordos com o setor mais reacionário da União Cívica - o mitrismo.

Hipólito Yrigoyen que chefiava - Comitê da União Cívica Radical em Buenos Aires surgiu como - herdeiro político de Além, repudiando os acordos da ala conservadora. Mas findos os agudos 
problemas econômicos de 1890 , atenuou-se a força do radicalismo. Nesta época estabeleceu-se a abstenção e o repúdio ao sistema governamental. Já em 1909 surgia uma nova posição conhecida como antipersonalista, que se opunha à conduta de Yrigoyen. Isto demonstra que as dissençōes internas continuavam.

$\mathrm{Na}$ verdade, o radicalismo era um movimento contraditório. Apesar de representar as aspirações das classes médias, seus dirigentes eram recrutados nas classes tradicionais e além disso não possuía um programa econômico definido. Sua luta girava em torno do sufrágio universal e era, portanto, uma luta pela incorporação ao sistema.

A reforma eleitoral de 1912 , com Saenz Peña no poder, veio atender às demandas crescentes deste partido e terminava com 0 seu período de abstenção eleitoral. Esta reforma era a manifestação de um processo de mudança politica em que os grupos tradicionais viram-se forçados a ceder diante das pressões dos novos setores.

A subida de Yrigoyen à presidéncia, em 1916, significou a aceitação por parte do radicalismo, da situação estabelecida e das limitações impostas pelo regime, contando apenas com um vago programa de defesa da Constituição e restabelecimento 134 da moralidade administrativa.

As divergências antes disfarçadas pelo objetivo comum de ascensão política começaram então a exteriorizar-se, culminando com a crise interna do radicalismo em 1924, quando surgiu a União Cívica Antipersonalista. Os conflitos agravaram-se principalmente quando o governo de Yrigoyen teve de enfrentar problemas econômicos e sociais. Apesar de seus projetos agrários não terem sido aprovados no
Congresso, estavam longe de propor uma alteração na estrutura de propriedade: eram projetos acanhados que visavam especialmente à implementação da colonização agropecuária e a organização de cooperativas agrícolas. Mesmo seu apoio restrito aos grupos industriais nascentes não afetava os interesses e o poder econômico da oligarquia.

Apesar disso, o governo de Yrigoyen abriu uma nova etapa de política econômica em que o Estado passava a intervir cada vez mais decisivamente nos assuntos econômicos do país.

Em relação ao movimento operário, a atuação de Yrigoyen foi imprecisa e contraditória. Se nos primeiros anos de seu governo apoiou greves reivindicatórias, obrigando as empresas a atenderem favoravelmente, como na greve dos ferroviários em 1917, já em fins deste mesmo ano enviou efetivos da Marinha para abafar a greve dos operários de frigoríficos, repetindo em 1921 severas medidas contra o movimento operário.

Yrigoyen vence novas eleições presidenciais em 1928 levando a bandeira da nacionalização do petróleo, mas permanece pouco tempo no poder. As dissenções internas da UCR agravaram-se neste período e os efeitos da retração econômica de 1929 contribuíram sobremaneira para que - governo caisse erh descrédito. Grupos radicais aliaram-se a setores conservadores para oporem-se à política considerada personalista de Yrigoyen e sua queda em 1930 marcou o auge da desorganização interna da UCR.

Outro aspecto importante do movimento é enfocado por Susana Bianchi. Ela estabelece as conexões entre o radicalismo e o peronismo ou, mais precisamente, a forma como se manteve o
Partido de Yrigoyen diante do populismo de Peron; mostra, num panorama claro, as bases politicas peronistas e suas proposições no plano econômico, político e social.

Diferente de Yrigoyen que representava os setores médios, Peron buscou a sustentação numa grande força política em disponibilidade: os operários urbanos. Em 1943, quando Secretário do Trabalho, iniciou na Argentina uma época conhecida como a era da "Justiça Social", atraindo com leis trabalhistas a adesão do setor operário. $E$, ainda, propondo defender uma política econômica nacionalista, angariou as simpatias da burguesia industrial argentina.

Porém, a classe média que re. presentava numericamente qua. se metade da população do pais reagiu contrariamente ao caráter operário do peronismo e nesta situação manteve-se o radicalis. mo durante o governo de Peron. Além disso, o radicalismo for. taleceu-se com a adesão de setores da oligarquia e dos indus. triais contrários à política pero. nista.

O fim da II Guerra Mundial trouxe conseqüências nefastas para a economia do país e afetou sensivelmente 0 governo de $\mathrm{Pe}$. ron. A crise da indústria nacional, - aumento de desempregados, a elevação do custo de vida são atribuidos à ineficiência de seu governo.

O radicalismo ganhava novos adeptos a medida que o peronis. mo se debilitava. Pressionada pela elevação do custo de vida, a classe média redobra sua oposição ao governo e, a partir de 1952, a Igreja, o Exército e alguns setores operários, antes aliados do peronismo, procuram aproxi. mação com o radicalismo. 
Assim, o radicalismo sobrevivia pela ação de forças muito heterogêneas acionando interesses muitas vezes opostos, responsáveis pela sua dúbia e contraditória atuação.

Apresentamos aqui apenas alguns aspectos do radicalismo argentino que é um fenômeno muito complexo. Para quem deseja conhecer a realidade argentina, vai encontrar nesta série de artigos uma rica informação histórica acerca de um longo período que se estende de 1890 a 1966.

Além de se esclarecer sobre os fatos e a conjuntura econômica que acompanhou a ação de forças sociais e políticas, o leitor tem a oportunidade de entrar em contato com uma documentação complementar importante, reunida no final do livro. Aí se encontram, por exemplo, desde manifestos da União Cívica Radical e seu programa de ação, até os manifestos da Junta Revolucionária de 1890, da Revolução de 1905, mensagem governamental de Yrigoyen em 1919, documentos sobre a Reforma Universitária etc.

Volia Regina Costa Kato

\section{As culturas negras}

Por Arthur Ramos. Rio de Janeiro; Livraria Editora da Casa do Estudante do Brasil, v. 3 (Coleção Arthur Ramos).

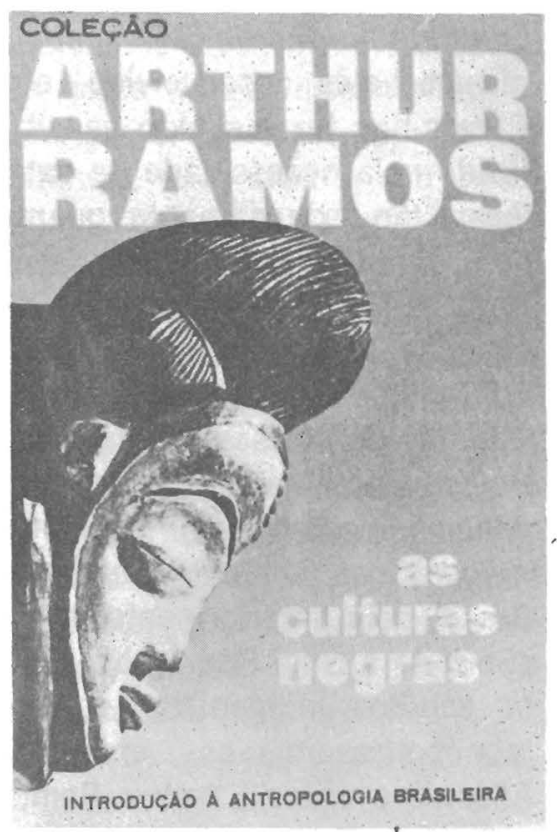

Esta obra faz parte de um conjunto mais amplo de estudos realizados pelo autor (ao todo 485 trabalhos publicados) em que determinados assuntos são tratados com mais vagar aqui ou ali, recebendo atenção específica. A análise dos fenômenos aculturativos e contra-aculturativos, por exemplo, é mais intensiva em outros textos do que neste de que nos ocupamos. O fenômeno da possessão pelos orixás, a mitologia, a literatura e as danças afro-brasileiras estão interpretados psicanaliticamente por Arthur Ramos no livro 0 negro brasileiro (ainda que a aplicação da psicanálise "européia" à situação dos negros no Brasil não seja de todo adequada, conforme realça Roger Bastide). Sobre as associações negras, dedicou um capítulo intitulado 0 espírito associativo do negro brasileiro, no livro $A$ aculturação ne- gra no Brasil. A respeito do folclore há um tomo específico: 0 folclore negro; sobre os fenômenos aculturativos, As culturas negras no Novo Mundo e $\mathbf{A}$ aculturação negra no Brasil.

Todas estas obras foram recomendadas pelo próprio autor, à medida que o texto sugeria maior profundidade, além de um extenso rol indicado na bibliografia final. Em As culturas negras não há preocupação interpretativa; trata-se de um estudo etnológico interessado em catalogar as culturas africanas que para cá foram transportadas. Os sincretismos que resultaram do processo aculturativo (transformação da magia em feitiçaria, do totemismo em festas populares e folclóricas, etc.) não cabem nos limites deste texto. A esse respeito citamos as palavras do autor: "Como já deixei assinalado, não abordarei neste volume o problema da mudança cultural e da aculturação, que será estudado noutro volume desta obra, visto que meu intento agora é identificar, pelo método comparativo, as origens tribais do Negro no Brasil, e assim reconstituir a sua personalidade cultural, perdida em séculos de escravidão e modificada pelas mudanças de sociedade e de cultura". (p. 50.)

Portanto, para se fazer justiça a um estudioso do porte de Arthur Ramos, é imprescindivel a lembrança de que sua obra flui entre um estudo e outro. Ousamos sugerir que esta, ora em resenha, seja tomada como introdutória, porque trata apenas da procedência (geográfica e cultural) dos negros brasileiros e da constatação de sua presença em determinadas regiões do País. 